\title{
Association of a MET genetic variant with autism-associated maternal autoantibodies to fetal brain proteins and cytokine expression
}

\author{
L Heuer $^{1,2}$, D Braunschweig ${ }^{1,2}$, P Ashwood ${ }^{2,3}$, J Van de Water ${ }^{1,2}$ and DB Campbell ${ }^{4,5}$
}

The contribution of peripheral immunity to autism spectrum disorders (ASDs) risk is debated and poorly understood. Some mothers of children with ASD have autoantibodies that react to fetal brain proteins, raising the possibility that a subset of ASD cases may be associated with a maternal antibody response during gestation. The mechanism by which the maternal immune system breaks tolerance has not been addressed. We hypothesized that the mechanism may involve decreased expression of the MET receptor tyrosine kinase, an ASD risk gene that also serves as a key negative regulator of immune responsiveness. In a sample of 365 mothers, including 202 mothers of children with ASD, the functional MET promoter variant rs $1858830 \mathrm{C}$ allele was strongly associated with the presence of an ASD-specific $37+73-\mathrm{kDa}$ band pattern of maternal autoantibodies to fetal brain proteins $(P=0.003)$. To determine the mechanism of this genetic association, we measured MET protein and cytokine production in freshly prepared peripheral blood mononuclear cells from 76 mothers of ASD and typically developing children. The MET rs $1858830 \mathrm{C}$ allele was significantly associated with MET protein expression $(P=0.025)$. Moreover, decreased expression of the regulatory cytokine IL-10 was associated with both the MET gene $C$ allele $(P=0.001)$ and reduced MET protein levels $(P=0.002)$. These results indicate genetic distinction among mothers who produce ASD-associated antibodies to fetal brain proteins, and suggest a potential mechanism for how a genetically determined decrease in MET protein production may lead to a reduction in immune regulation.

Translational Psychiatry (2011) 1, e48; doi:10.1038/tp.2011.48; published online 18 October 2011

\section{Introduction}

Autism spectrum disorders (ASDs) are a complex, behaviorally defined group of developmental disorders characterized by social deficits, language impairments and repetitive behaviors with restricted interests. Previous studies of twins and sibling recurrence risk have suggested that ASD is among the most heritable of neuropsychiatric disorders, encouraging extensive research into the genetic basis of ASD risk. ${ }^{1-3}$ However, a more recent twin study reported that susceptibility to ASD has a much lower genetic heritability component, while the more substantial component of risk was explained by environmental factors in a shared twin environment. ${ }^{4}$ This would indicate that the gestational environment, susceptible to genetic regulation by both the fetus and the mother, might be a major factor in determining ASD risk. The genetic risk may lie in (a) the direct impact of genetic regulation on brain development, (b) altering sensitivities to environmental factors and (c) disruption of autonomic and peripheral organ development and function that may influence brain development. In this regard, there is a growing body of evidence that, among risk factors, immune system dysregulation may be a feature in this neurodevelopmental disorder ${ }^{5-7}$
Growing evidence indicates that maternal immune dysfunction during gestation may contribute to ASD risk. In animal models, maternal immune activation during gestation leads to behavioral changes in subsequent offspring. ${ }^{8}$ In humans, epidemiologic analyses reported that a family history of autoimmune disorders was more common in families of children with ASD, ${ }^{9,10}$ and that immune-mediated disorders (psoriasis, maternal asthma and allergy) occurred more often around the time of pregnancy in the mothers of children with ASD compared with the mothers with typically developing (TD) children. ${ }^{11}$ One early report demonstrated that serum from a mother of a child with ASD showed IgG antibody reactivity to rodent Purkinje cells; this same serum was then injected into gestating mice and shown to elicit behavioral deficits in the offspring. ${ }^{12}$ In another study, 11 mothers of children with ASD and their affected children were found to have consistent patterns of antibody reactivity against rat prenatal brain proteins. ${ }^{13}$ Further studies have highlighted that this reactivity is to fetal and not adult brain proteins. ${ }^{14}$ Our recent studies have demonstrated reactivity against fetal brain proteins at $\sim 37$ and $73 \mathrm{kDa}$ in plasma from 7 of 61 $(11.5 \%)$ mothers of children with ASD but not in 102 mothers of TD children. ${ }^{15}$ Injection of rhesus monkeys with human IgG

\footnotetext{
${ }^{1}$ Department of Internal Medicine, University of California, Davis, Davis, CA, USA; ${ }^{2}$ University of California, Davis M.I.N.D. Institute, Davis, CA, USA; ${ }^{3}$ Department of Medical Microbiology, University of California, Davis, Davis, CA, USA; ${ }^{4}$ Department of Psychiatry and the Behavioral Sciences, Keck School of Medicine, University of Southern California, Los Angeles, CA, USA; ${ }^{5}$ Zilkha Neurogenetic Institute, Keck School of Medicine, University of Southern California, Los Angeles, CA, USA Correspondence: Dr DB Campbell, 213 Zilkha Neurogenetic Institute, Keck School of Medicine, University of Southern California, Los Angeles, CA 90089, USA or Dr J Van de Water, Division of Rheumatology/Allergy and Clinical Immunology; 451 E. Health Sciences Dr., Suite 6510; University of California Davis; Davis, CA 95616, USA.
}

E-mail: dbcampbe@usc.edu or javandewater@ucdavis.edu

Keywords: autism; gene; immune; maternal; cytokine

Received 21 June 2011; revised 2 September 2011; accepted 5 Septemeber 2011 
from mothers of children with ASD (who were positive for fetal brain antibodies) during gestation resulted in increased stereotypical behavior and hyperactivity in the offspring when compared with the offspring of rhesus monkeys injected with IgG from mothers of TD children. ${ }^{16}$ Evidence of a potential role for these antibodies with respect to changes in neurodevelopment was also noted in a recent murine model. ${ }^{17}$

Although the preponderance of evidence points to an immune-mediated etiology in some cases of ASD, the biological mechanism of the maternal immune dysfunction remains unclear. In an independent line of study, we described robust genetic association with ASD of a functional variant in the $5^{\prime}$ promoter of the gene encoding the MET receptor tyrosine kinase. ${ }^{18}$ The $M E T$ promoter variant, rs1858830, is a common G-to-C single-nucleotide polymorphism (SNP); the 'C' allele is inherited by individuals with ASD more often than predicted by chance and is more common in individuals with ASD than in a sample of the general population. ${ }^{18-20}$ Stratifying ASD subpopulations demonstrated that association of the $M E T$ ' $C$ ' allele is enriched in individuals with co-occurring ASD and gastrointestinal conditions, ${ }^{21}$ and in the social and communication domains of ASD. $^{22}$ Independent evidence indicates decreased expression of the ligand for the MET receptor, hepatocyte growth factor (HGF), in serum of individuals with co-occurring ASD and gastrointestinal conditions. ${ }^{23}$ In addition to its roles in brain development and gastrointestinal repair, the MET receptor tyrosine kinase is a key negative regulator of immune responsiveness. Ligation of the MET receptor by its HGF ligand prevents lupus nephritis in chronic graft-versus-host disease, ${ }^{24}$ ameliorates the progression of experimental autoimmune myocarditis ${ }^{25}$ and suppresses collagen-induced arthritis in mice. ${ }^{26} \mathrm{MET}$ also induces morphogenic changes in antigen-presenting cells. Importantly, MET signaling induces a tolerogenic phenotype in antigen-presenting cells through the induction of IL-10, without affecting their antigen-presenting capabilities. ${ }^{27,28}$ This tolerogenic phenotype induces $T$ regulatory cells in response to antigen that would otherwise have broken tolerance and potentially lead to autoimmunity. ${ }^{28}$ MET protein expression is decreased in postmortem brain of individuals with the MET ' $C$ ' allele. ${ }^{29}$ If the same genotypeexpression correlation is observed in the immune system, then one prediction is that disrupted MET signaling may confer susceptibility to immune dysregulation. We hypothesized that MET disruption would be associated with markers of immune dysregulation in mothers of children with ASD. To test this hypothesis, we examined the MET promoter variant rs1858830 ' $C$ ' allele in the context of ASD-specific maternal antibodies to fetal brain proteins, as well as the cytokine profile of peripheral blood cells following immune challenge.

\section{Materials and methods}

Subjects. All mothers, $(n=365)$ including those of children with an ASD $(n=202)$ and those of TD control children $(n=163)$, participated in the Childhood Autism Risks from Genetics and the Environment (CHARGE) study. ${ }^{30}$ Those children enrolled in the study met the following criteria: (a) they were between the ages of 24 and 60 months at the time of enrollment, (b) lived with at least one biologic parent, (c) had a parent who spoke either English or Spanish, (d) were born in the state of California and (e) resided in the catchment areas of a specified list of regional centers in Northern California. The CHARGE study is an ongoing population-based case-control study. This study protocol followed the ethical guidelines of the most recent Declaration of Helsinki, and was approved by the institutional review boards at the University of California, Davis, The State of California Department of Developmental Services, and the University of Southern California. Informed consent was obtained before participation.

To confirm the initial diagnosis, all children enrolled in the study were assessed at the UC Davis M.I.N.D. Institute. The diagnosis of ASD was confirmed in all subjects using the standardized Autism Diagnostic Interview-Revised (ADI$R)^{31}$ and the Autism Diagnostic Observation Schedule (ADOS) modules 1 or $2^{32-35}$ The ADI-R provides a standardized, semi-structured interview and a diagnostic algorithm for the DSM-IV ${ }^{36}$ and ICD-10 definitions of autism. ${ }^{37}$ All of the CHARGE study clinical assessment personnel have attained research reliability on the ADI-R and the ADOS. The Social Communication Questionnaire was used to screen for behavioral and developmental characteristics of ASD among TD controls; children who scored above the screening cutoff score of 15 were fully assessed using the ADI-R and ADOS. Those controls that met criteria for autistic disorder were classified as ASD. Controls who did not meet criteria for ASD were classified as TD.

Autoantibodies. Western blot data collected and analyzed in a previous study was used for the association analyses described herein. Western blots were performed as previously described using fetal monkey brain extract. ${ }^{15,38}$

Genotyping the ASD-associated MET promoter variant rs1858830. As the rs 1858830 SNP falls within a highly GCrich region, indirect genotyping methods fail when using genomic DNA. A 652-bp fragment containing the rs1858830 SNP was amplified from $15 \mathrm{ng}$ genomic DNA with primers $5^{\prime}-$ GATTTCCCTCTGGGTGGTG-3' (Forward) and 5'-CAAGC CCCATTCTAGTTTCG-3' (Reverse). Each 20- $\mu$ l reaction included $15 \mathrm{ng}$ genomic DNA, $1 \mu \mathrm{M}$ each primer, 5\% dimethyl sulfoxide, $15 \mathrm{mM} \mathrm{MgCl}_{2}, 0.25 \mathrm{~mm}$ each dNTP (dATP, dCTP, dGTP and dTTP), $2.5 \mathrm{U}$ AmpliTaq Gold DNA Polymerase (ABI, Carlsbad, CA, USA) and 0.2U Turbo pfu DNA polymerase (Stratagene, Santa Clara, CA, USA). Cycling conditions were: $95^{\circ} \mathrm{C}$ for $5 \mathrm{~min}$ followed by 35 cycles of $95^{\circ} \mathrm{C}$ for $30 \mathrm{~s}, 61^{\circ} \mathrm{C}$ for $30 \mathrm{~s}$ and $72{ }^{\circ} \mathrm{C}$ for $1 \mathrm{~min}$. Specific amplification of the 652-bp product was confirmed by agarose gel electrophoresis. Each PCR product was subjected to direct re-sequencing using an $A B I 3730 x \mid$ using Big Dye Terminator chemistry. Genotype at the MET rs1858830 locus was determined from the sequencing result using Sequencher software (Gene Codes, Ann Arbor, MI, USA).

Cell culture and stimulation. CHARGE is an ongoing study for which we have collected and banked both plasma 
and DNA that allowed us to retroactively analyze subjects for both autoantibody production and genotype at the MET rs1858830 locus. However, cytokine production in response to immune challenge must be done on freshly isolated peripheral blood mononuclear cells (PBMCs). Therefore, a random subset of 76 mothers $(22 \mathrm{C} / \mathrm{C}, 33 \mathrm{C} / \mathrm{G}$ and $21 \mathrm{G} / \mathrm{G})$, prospective to study initiation, was used to assess the functional cytokine response in relation to MET rs1858830 genotype. Whole blood was collected through venipuncture into yellow top citrate tubes (BD, Franklin Lakes, NJ, USA) according to study protocol, and centrifuged at $900 \mathrm{~g}$ for $10 \mathrm{~min}$ to pellet cells. Plasma was collected and immediately frozen in $0.5 \mathrm{ml}$ aliquots at $-80^{\circ} \mathrm{C}$ until assayed by western blot for the presence of anti-fetal brain antibodies. The cell pellet was then adjusted to appropriate density with HBSS and layered over Histopaque density gradient (Sigma, St Louis, MO, USA) followed by centrifugation at $600 \mathrm{~g}$ for $30 \mathrm{~min}$. The PBMC layer was removed and washed two additional times at $900 \mathrm{~g}$ for $10 \mathrm{~min}$ at which point cells were counted with a hemocytometer, and 300000 cells per well were plated into 96 -well round bottom plates. Cells were then allowed to rest $24 \mathrm{~h}$ before administration of $5 \mu \mathrm{g} \mathrm{ml}^{-1}$ lipopolysaccharide for $48 \mathrm{~h}$ to induce the production of an innate immune response. After stimulation, cell culture supernatants and cell pellets were frozen at $-80^{\circ} \mathrm{C}$ until assayed for cytokine levels and MET protein levels, respectively.

Determination of cytokine levels. As a measure of innate immune reactivity following lipopolysaccharide stimulation, cell culture supernatants were analyzed for seven different cytokine and chemokines, including IL-6, GM-CSF, IL-1, IL$12 p 40$, TNF- $\alpha$, MIP-1 $\beta$ and IL-10. Levels were determined using a commercially available multiplex bead-based kit and run according to manufacturer's instructions (Millipore, Billerica, MA, USA). Briefly, $25 \mu$ of cell culture supernatant was incubated with anti-cytokine-conjugated beads in a 96well filter-bottom plate on a plate shaker overnight at $4{ }^{\circ} \mathrm{C}$. The beads were then washed using a vacuum manifold, and biotin-conjugated detection antibodies were added for a 1-h incubation, followed by the subsequent addition of streptavidin-PE for $30 \mathrm{~min}$. The plates were then read on a Bio-Plex 100 (BioRad, Hercules, CA, USA), and analyzed using Bio-Plex Manager software using a 5-point standard curve. Reference samples were run on each plate to determine assay consistency.

Determination of MET protein levels. After the supernatant was extracted, the cultured cells were used to determine the expression of the membrane-bound MET protein. The cell pellet was resuspended in $60-\mu$ l Novagen Widescreen protein extraction reagent. Protein assays were performed with the Luminex XMAP technology with a beadbased MET (HGF-Receptor) ELISA kit (Novagen, Rockland, MA, USA), by manufacturer's protocol. Briefly, the isolated protein was mixed with capture beads containing primary antibody directed to MET (HGF-Receptor; Novagen), followed by overnight shaking incubation at $4{ }^{\circ} \mathrm{C}$. Protein was measured on the Bio-Plex Suspension Array System (Bio-Rad, Hercules, CA, USA) at the Beckman Center Core at the USC Norris Cancer Center. Data acquisition and analysis were performed using the Bio-Plex Manager software (Bio-Rad).

Statistical analyses. The $\chi^{2}$ was used to analyze the association of MET rs1858830 genotype with the presence of maternal antibody. Allelic $\chi^{2}$ results are presented; genotypic $\chi^{2}$ results are similar. Genotype-dependent differences in MET protein and cytokine production were determined by analysis of variance followed by post-hoc Tukey-Kramer tests. Linear regression was used to determine correlation between MET protein expression and cytokine levels. Bonferroni correction for multiple comparisons was used to account for the analysis of multiple cytokines.

\section{Results}

Maternal antibody patterns associated with ASD risk. In a previous report with the CHARGE sample, ${ }^{30}$ association with ASD risk was demonstrated for a $37+73-\mathrm{kDa}$ band pattern of maternal antibodies reactive to fetal brain proteins in 61 mothers of children with ASD but not 102 mothers of TD children. ${ }^{15}$ Data for the current study were derived from an expanded study to include a total of 202 mothers of children with an ASD and 163 mothers of TD children. ${ }^{38}$ Specificity of the combined $37+73-\mathrm{kDa}$ band pattern with ASD risk was maintained in this larger sample. The $37+73-\mathrm{kDa}$ band pattern (as illustrated in conjunction with Table 1) was present in 19 of 202 (9\%) mothers of children with an ASD, and none of the 163 mothers of TD children (Table 1).

Association of MET rs1858830 C allele with ASDassociated maternal antibody band patterns. We next stratified the sample by maternal antibody patterns that have been shown to be associated with ASD risk in the offspring, and performed genetic association tests with the MET rs1858830 genotype. Among the 19 mothers who were positive for the $37+73-\mathrm{kDa}$ band pattern, 11 (58\%) were homozygous for the ASD-associated MET rs1858830 C allele, 7 (37\%) were $\mathrm{C} / \mathrm{G}$ heterozygotes and one $(5 \%)$ was homozygous for the $\mathrm{G}$ allele (Table 2). Among the 183 mothers of children with ASD who were negative for the $37+73-\mathrm{kDa}$ band pattern, 51 (28\%) were C/C homozygous, 79 (43\%) were C/G heterozygous and 53 (29\%) were G/G homozygous (Table 2). This MET C allele frequency of $76 \%$ in the 19 mothers with the $37+73-\mathrm{kDa}$ band pattern was significantly higher than the $49 \%$ C allele frequency observed

Table 1 Incidence of antibody reactivity to fetal brain proteins in mothers of children with an ASD compared with mothers of TD children

\begin{tabular}{|c|c|c|}
\hline Diagnosis of offspring & $N$ & $\begin{array}{c}\text { Positive for 37/73-kDa } \\
\text { band pattern (\%) }\end{array}$ \\
\hline $\begin{array}{l}\text { ASD } \\
\text { TD } \\
\text { ASD + TD }\end{array}$ & $\begin{array}{l}202 \\
163 \\
365\end{array}$ & $\begin{array}{c}19(9)^{\star} \\
0(0) \\
19(5)\end{array}$ \\
\hline
\end{tabular}

Abbreviations: ASD, autism spectrum disorder; TD, typically developing. Figure (B) illustrates the $37 / 73-\mathrm{kDa}$ band pattern by western blot where lane 1 represents an antibody-positive mother of a child with an ASD, and lane 2 represents the mother of a TD control. ${ }^{*} P<0.0001$ ASD vs TD. 
Table 2 Association of $M E T$ rs $1858830 \mathrm{C}$ allele with the ASD-associated $37+73-\mathrm{kDa}$ band pattern

\begin{tabular}{lrrrrc}
\hline 37/73-kDa bands & $\boldsymbol{N}$ & $\begin{array}{c}\text { MET } \\
\boldsymbol{C} / \boldsymbol{C}(\%)\end{array}$ & $\begin{array}{c}\text { MET } \\
\boldsymbol{C} / \mathbf{G}(\%)\end{array}$ & $\begin{array}{c}\text { MET } \\
\mathbf{G} / \mathbf{G}(\%)\end{array}$ & $\begin{array}{c}\text { Allelic } \\
\chi^{2} \mathrm{P}\end{array}$ \\
\hline ASD positive & 19 & $11(58)$ & $7(37)$ & $1(5)$ & Reference \\
ASD negative & 183 & $51(28)$ & $79(43)$ & $53(29)$ & 0.002 \\
ASD + TD negative & 346 & $101(29)$ & $154(45)$ & $91(26)$ & 0.003
\end{tabular}

Abbreviations: ASD, autism spectrum disorder; TD, typically developing.

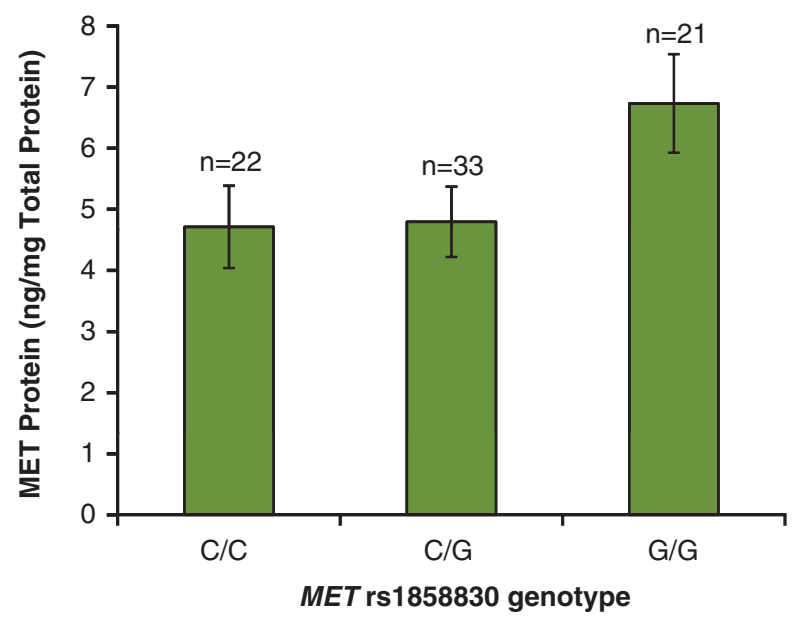

Figure 1 Association of MET rs1858830 genotype with MET protein expression in peripheral blood mononuclear cells (PBMCs). MET protein expression was reduced 1.4-fold in mothers of genotype $\mathrm{C} / \mathrm{C}\left(4.7 \pm 0.7 \mathrm{ng} \mathrm{mg}^{-1}\right.$ total protein) compared with mothers of genotype $\mathrm{G} / \mathrm{G}\left(6.7 \pm 0.8 \mathrm{ng} \mathrm{mg}^{-1}\right.$ total protein) $(P=0.030)$. MET protein expression was also decreased in mothers of genotype $\mathrm{C} / \mathrm{G}$ compared with mothers of genotype $\mathrm{G} / \mathrm{G}(P=0.025)$. There was no significant difference in MET protein expression between mothers of genotype $C / C$ and $C / G$ $(P=0.463)$.

in the 183 mothers of children with ASD who did not exhibit the $37+73-\mathrm{kDa}$ band pattern $(P=0.002$; Table 2). Among 346 mothers of both ASD and TD children who were negative for the $37+73-\mathrm{kDa}$ band pattern, 101 (29\%) were C/C, 154 (45\%) were C/G and 91 (26\%) were G/G (Table 2). The $76 \%$ frequency of the MET C allele in mothers with the $37+73-$ $\mathrm{kDa}$ band pattern was also significantly higher than the $51 \%$ $C$ allele frequency observed in all 346 mothers lacking the band pattern $(P=0.003$; Table 2$)$.

\footnotetext{
Association of MET rs1858830 genotype with MET protein levels in PBMCs of nonpregnant mothers. We previously reported an association of the MET C allele with decreased MET protein levels in postmortem brain samples from individuals with ASD. ${ }^{29}$ To determine if MET rs 1858830 genotype also predicts MET protein levels in peripheral blood, we measured MET protein levels in stimulated PBMCs isolated from 76 mothers of ASD and TD children, as MET is only expressed on immune cells in response to activation. As anticipated, results were similar to those observed in postmortem brain where the expression of MET protein was significantly reduced. In mothers with the MET rs1858830 C/C genotype, MET protein expression was reduced 1.4-fold in PBMCs compared with mothers with
}
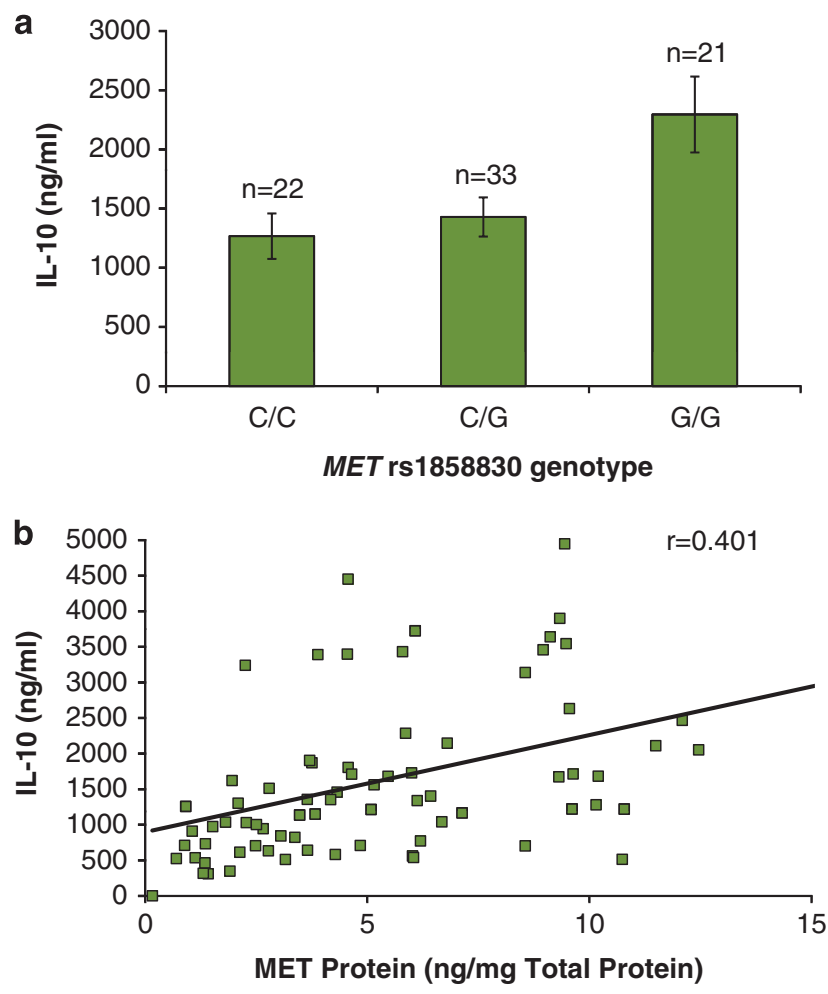

Figure 2 Correlation of both MET rs 1858830 genotype (a) and MET protein levels (b) with IL-10 expression in peripheral blood mononuclear cells (PBMCs). (a) IL-10 protein is increased 1.8-fold in G/G genotype mothers $\left(2295 \pm 321 \mathrm{ng} \mathrm{mg}^{-1}\right.$ ) compared with $\mathrm{C} / \mathrm{C}$ genotype mothers $\left(1267 \pm 192 \mathrm{ng} \mathrm{mg}^{-1}\right)(P=0.001)$. IL-10 protein is increased 1.6-fold in $\mathrm{G} / \mathrm{G}$ genotype mothers compared with $\mathrm{C} / \mathrm{G}$ genotype mothers $\left(1429 \pm 165 \mathrm{ng} \mathrm{mg}^{-1}\right)(P=0.005)$. (b) Linear regression indicates highly significant correlation $(r=0.401 ; P=0.003)$ between expression of MET protein and expression of IL-10 protein.

the $\mathrm{G} / \mathrm{G}$ genotype $(P=0.030$; Figure 1$)$. MET protein was also significantly decreased in mothers with the $C / G$ genotype compared with the $\mathrm{G} / \mathrm{G}$ genotype $(P=0.025$; Figure 1).

Correlation of both MET C allele and reduced MET protein levels with decreased cytokine IL-10 production in mothers. In the same PBMCs used for cellular MET protein level analysis, we also measured the production of seven cytokines (IL-1, IL-6, IL-10, IL-12(p40), GM-CSF, MIP$1 \beta$ and TNF- $\alpha$ ) following stimulation with lipopolysaccharide of PBMC cultures. Production of the regulatory cytokine IL-10 was significantly associated with $M E T$ rs 1858830 genotype and MET protein levels. The production of IL-10 was decreased 1.8-fold in mothers of genotype $\mathrm{C} / \mathrm{C}$ compared with mothers of genotype $\mathrm{G} / \mathrm{G}(P=0.001$; Figure $2 \mathrm{a})$. As expected by the association of MET genotype to MET protein levels, the production of IL-10 was also positively correlated with the amount of MET protein $(P=0.002$; Figure $2 b)$. It is important to note that the significance of both of these results survive Bonferroni correction for analysis of seven analytes. The effect of MET genotype was specific to IL-10 as there was no correlation to expression of the other six cytokines tested. 


\section{Discussion}

The results of this study suggest that the functional MET promoter variant rs $1858830 \mathrm{C}$ allele is associated with the presence of ASD-associated maternal antibodies to fetal brain proteins. The convergence of these two previously distinct associations with ASD risk (that of maternal antibodies to fetal brain proteins and of the MET C allele) provides the first link between an ASD susceptibility gene and a functional immunerelated outcome to that gene.

MET is a receptor tyrosine kinase, serving different functions in distinct cell types, including proliferation, motogenesis, survival and differentiation. MET is best understood as an oncogene involved in the metastasis of several cancers: somatic gain-of-function mutations lead to dramatically increased signaling via the MET receptor, and uncontrolled cell proliferation and migration. ${ }^{39} \mathrm{MET}$ is also involved in mediating HGF signaling in a number of developmental, physiological and repair processes, including liver regeneration, ${ }^{40}$ gastrointestinal repair, ${ }^{41-43}$ and in serving as a part of a negative feedback loop in immune responses. ${ }^{27,44,45}$ The MET C allele decreases transcription and results in reduced MET receptor tyrosine kinase protein in postmortem brain samples. ${ }^{18,29}$
In the current study, we demonstrate that the METC allele is also associated with decreased expression of MET protein in the immune system. As MET functions as a key negative regulator of immune function, the association of a functional genetic variant and ASD suggests a possible mechanism through which ASD-specific maternal antibodies to fetal brain proteins are generated. In addition to its role in autoimmunity, the MET receptor ligand HGF has also been shown to attenuate inflammatory conditions such as acute hyper responsiveness and airway remodeling in a murine model of asthma, ${ }^{46}$ as well as the suppression of acute and chronic cardiac transplant rejection in the mouse. ${ }^{47}$ While animal models lend support to an immunosuppressive role, the exact mechanism by which HGF exerts its effects on the immune system has not been fully elucidated. The MET receptor has been detected on monocytes/macrophages, dendritic cells and B cells, but not on $\mathrm{T}$ cells, even though HGF has been implicated in the adhesion and migration of memory T cells. ${ }^{27,44,48-51}$ Interestingly, MET protein expression is low to undetectable in inactive cells but increases dramatically in response to cellular activation. ${ }^{4,51}$ In this study, we provide evidence that subjects harboring the $M E T$ ' $C$ ' allele are deficient in a crucial immunoregulatory molecule, IL-10, that may leave them more susceptible to prolonged inflammatory conditions.

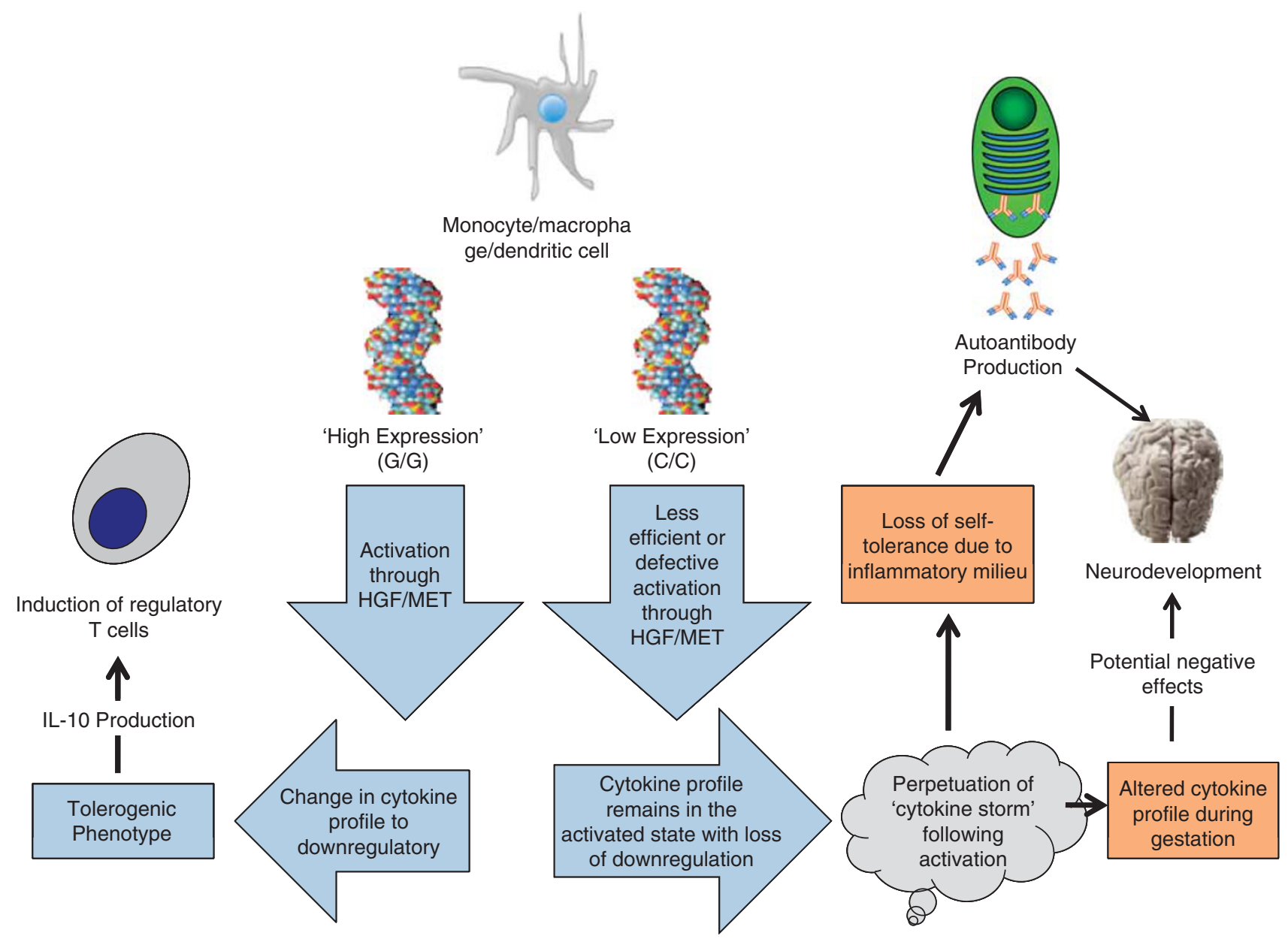

Figure 3 Proposed model of the mechanism by which maternal MET genotype predisposes, via immune dysregulation, toward neurodevelopmental alterations characteristic of ASD. 
Interleukin-10 is a well-described immunosuppressive cytokine that has been shown to be upregulated in animal models, in which HGF is important in the prevention of autoimmunity. ${ }^{25,26,52}$ In addition, in vitro studies on the effects of HGF on both human and mouse antigen-presenting cells implicate IL-10 as a major contributor to the reported antiinflammatory effects. ${ }^{28,53} \mathrm{IL}-10$ has been reported to be decreased in children with ASD compared with controls, ${ }^{54-56}$ but only in the context of innate cell activation. In the context of adaptive immune activation or at baseline, IL-10 levels in children with ASD are unchanged. ${ }^{57-61}$ However, there have not been any studies investigating the potential role of IL-10 dysregulation in the mothers of children with ASD.

In this study, we describe a decrease in levels of IL-10 that is significantly correlated with levels of MET protein expression. We had anticipated an increase in inflammatory cytokines as MET signaling has been shown to directly modulate the inflammatory response through phosphorylation of GSK3 $\beta$; however, unlike other studies we did not observe a significant increase in pro-inflammatory cytokine production. ${ }^{53}$ This is likely attributed to both the cellular composition of the stimulated cultures (the use of whole PBMC in our study vs the use of bone marrow-derived macrophages in animal studies) as well as the timing of cytokine measurements (48 vs $24 \mathrm{~h}$ ). IL-10 is most often attributed with the resolution of an inflammatory response. It may be that signaling through the MET receptor functions to shorten the duration of the inflammatory response and not necessarily the magnitude, thereby allowing sustained inflammation in mothers with the $M E T$ ' $C$ ' allele. Such sustained inflammation would provide an environment conducive to loss of tolerance, thereby increasing the risk of autoantibody production, or potentiate a change in the cytokine profile during pregnancy that could negatively affect proper neurodevelopment (Figure 3).

A limitation of this study, and of our predicted model, is the lack of data indicating the factor responsible for initiation of the inflammatory response. While the $M E T$ ' $C$ ' allele may provide susceptibility toward reduced immune regulation, an environmental trigger such as infection, xenobiotic exposure or other stressor is still required to initiate an immune response. This may partially explain why the ' $C$ ' allele is evenly distributed among the population but is highly prevalent in mothers who exhibit markers of immune dysregulation, that is, autoantibody production. Future studies in a prospective model that will allow for tracking of environmental insults are needed to explore this mechanism in further detail.

Several studies have now addressed the potential role for maternal antibodies to fetal brain proteins in ASD. ${ }^{12-17,38}$ While each of these studies demonstrated both antibody specificity as well as a potential pathologic significance of the maternal autoantibodies, the current study is the first to present evidence suggesting a genetic polymorphism associated with the production of these antibodies. We fully acknowledge that no single gene or environmental factor will account for the entirety of ASD etiologies, and thus our focus on one ASD candidate gene, the MET receptor tyrosine kinase, was based on its bi-functional role in brain and immune development. Our observations that MET rs 1858830 genotype predicts MET protein expression in the immune system, and that lower MET protein levels are correlated with lower regulatory cytokine levels, provides mechanistic support for this focus. The studies described herein represent the beginning of our investigation into the potential mechanism(s) by which the maternal immune system becomes susceptible to the generation of antibodies to fetal brain tissue. Identification of a predisposing genetic factor such as MET will contribute greatly toward the understanding of the mechanisms involved in a subset of ASD cases.

\section{Conflict of interest}

The authors declare no conflicts of interest.

Acknowledgements. Shaine Jones, Nicole Grepo, Paul Duncanson and Kasey Rivas provided expert technical assistance. We gratefully acknowledge the resources provided by the Childhood Autism Risk due to Genetics and the Environment (CHARGE) Consortium and the participating CHARGE families. This work was supported in part by NIEHS 1P01ES11269-01 (JV, PA, LH and DB), US EPA Grant R829388 (JV and PA), NIEHS 1 R01-ES015359 (JV, PA and LH,) and the Autism Speaks Foundation (JV, DBC and PA).

1. Gupta AR, State MW. Recent advances in the genetics of autism. Biol Psychiatry 2007; 61 429-437.

2. Geschwind DH, Levitt P. Autism spectrum disorders: developmental disconnection syndromes. Curr Opin Neurobiol 2007; 17: 103-111.

3. Levitt $P$, Campbell DB. The genetic and neurobiologic compass points toward common signaling dysfunctions in autism spectrum disorders. J Clin Invest 2009; 119: 747-754.

4. Hallmayer J, Cleveland S, Torres A, Phillips J, Cohen B, Torigoe T et al. Genetic heritability and shared environmental factors among twin pairs with autism. Arch Gen Psychiatry 2011 Jul 4 .

5. Ashwood P, Van de Water J. A review of autism and the immune response. Clin Dev Immunol 2004; 11: 165-174.

6. Ashwood P, Wills S, Van de Water J. The immune response in autism: a new frontier for autism research. J Leukoc Biol 2006; 80: 1-15.

7. Garbett K, Ebert PJ, Mitchell A, Lintas C, Manzi B, Mirnics K et al. Immune transcriptome alterations in the temporal cortex of subjects with autism. Neurobiol Dis 2008; 30: 303-311.

8. Boksa P. Effects of prenatal infection on brain development and behavior: a review of findings from animal models. Brain Behav Immun 2010; 24: 881-897.

9. Comi AM, Zimmerman AW, Frye VH, Law PA, Peeden JN. Familial clustering of autoimmune disorders and evaluation of medical risk factors in autism. $J$ Child Neurol 1999; 14: 388-394.

10. Atladóttir HÓ, Thorsen $P$, stergaard L, Schendel DE, Lemcke S, Abdallah M et al. Maternal infection requiring hospitalization during pregnancy and autism spectrum disorders. J Autism Dev Disord 2010; 40: 1423-1430.

11. Croen LA, Grether JK, Yoshida CK, Odouli R, Van de Water J. Maternal autoimmune diseases, asthma and allergies, and childhood autism spectrum disorders: a case-control study. Arch Pediatr Adolesc Med 2005; 159: 151-157.

12. Dalton P, Deacon R, Blamire A, Pike M, McKinlay I, Stein J et al. Maternal neuronal antibodies associated with autism and a language disorder. Ann Neurol 2003; 53: 533-537.

13. Zimmerman AW, Connors SL, Matteson KJ, Lee LC, Singer HS, Castaneda JA et al. Maternal antibrain antibodies in autism. Brain Behav Immun 2007; 21: 351-357.

14. Singer HS, Morris CM, Gause CD, Gillin PK, Crawford S, Zimmerman AW. Antibodies against fetal brain in sera of mothers with autistic children. J Neuroimmunol 2008; 194: $165-172$.

15. Braunschweig D, Ashwood P, Krakowiak P, Hertz-Picciotto I, Hansen R, Croen LA et al. Autism: maternally derived antibodies specific for fetal brain proteins. Neurotoxicology 2008; 29: 226-231.

16. Martin LA, Ashwood P, Braunschweig D, Cabanlit M, Van de Water J, Amaral DG. Stereotypes and hyperactivity in rhesus monkeys exposed to $\mathrm{lg} G$ from mothers of children with autism. Brain Behav Immun 2008; 22: 806-816.

17. Singer HS, Morris C, Gause C, Pollard M, Zimmerman AW, Pletnikov M. Prenatal exposure to antibodies from mothers of children with autism produces neurobehavioral alterations: a pregnant dam mouse model. J Neuroimmunol 2009; 211: 39-48.

18. Campbell DB, Sutcliffe JS, Ebert PJ, Militerni R, Bravaccio C, Trillo $S$ et al. A genetic variant that disrupts MET transcription is associated with autism. Proc Natl Acad Sci USA 2006; 103: $16834-16839$.

19. Campbell DB, Li C, Sutcliffe JS, Persico AM, Levitt P. Genetic evidence implicating multiple genes in the MET receptor tyrosine kinase pathway in autism spectrum disorder. Autism Res 2008; 1: 158-168. 
20. Jackson PB, Boccuto L, Skinner C, Collins JS, Neri G, Gurrieri F et al. Further evidence that the rs $1858830 \mathrm{C}$ variant in the promoter region of the MET gene is associated with autistic disorder. Autism Res 2009; 2: 232-236.

21. Campbell DB, Buie TM, Winter H, Bauman M, Sutcliffe JS, Perrin JM et al. Distinct genetic risk based on association of MET in families with co-occurring autism and gastrointestina conditions. Pediatrics 2009; 123: 1018-1024.

22. Campbell DB, Warren D, Sutcliffe JS, Lee EB, Levitt P. Association of MET with social and communication phenotypes in individuals with autism spectrum disorder. Am J Med Genet B Neuropsychiatr Genet 2010; 153B: 438-446.

23. Russo AJ, Krigsman A, Jepson B, Wakefield A. Decreased serum hepatocyte growth factor (HGF) in autistic children with severe gastrointestinal disease. Biomark Insights 2009; 181-190.

24. Kuroiwa T, Iwasaki T, Imado T, Sekiguchi M, Fujimoto J, Sano H. Hepatocyte growth factor prevents lupus nephritis in a murine lupus model of chronic graft-versus-host disease. Arthritis Res Ther 2006; 8: R123.

25. Futamatsu H, Suzuki J, Mizuno S, Koga N, Adachi S, Kosuge H et al. Hepatocyte growth factor ameliorates the progression of experimental autoimmune myocarditis: a potential role for induction of T helper 2 cytokines. Circ Res 2005; 96: 823-830.

26. Okunishi K, Dohi M, Fujio K, Nakagome K, Tabata Y, Okasora T et al. Hepatocyte growth factor significantly suppresses collagen-induced arthritis in mice. J Immunol 2007; 179: 5504-5513.

27. Okunishi K, Dohi M, Nakagome K, Tanaka R, Mizuno S, Matsumoto K et al. A novel role of hepatocyte growth factor as an immune regulator through suppressing dendritic cell function. J Immunol 2005; 175: 4745-4753.

28. Rutella S, Bonanno G, Procoli A, Mariotti A, de Ritis DG, Curti A et al. Hepatocyte growth factor favors monocyte differentiation into regulatory interleukin (IL)-10++IL-12low/neg accessory cells with dendritic-cell features. Blood 2006; 108: 218-227.

29. Campbell DB, D'Oronzio R, Garbett K, Ebert PJ, Mirnics K, Levitt P et al. Disruption of cerebral cortex MET signaling in autism spectrum disorder. Ann Neurol 2007; 62: 243-250.

30. Hertz-Picciotto I, Croen LA, Hansen R, Jones CR, van de Water J, Pessah IN. The CHARGE study: an epidemiologic investigation of genetic and environmental factors contributing to autism. Environ Health Perspect 2006; 114: 1119-1125.

31. Lord C, Pickles A, McLennan J, Rutter M, Bregman J, Folstein S et al. Diagnosing autism: analyses of data from the Autism Diagnostic Interview. J Autism Dev Disord 1997; 27: 501-517.

32. DiLavore PC, Lord C, Rutter M. The pre-linguistic autism diagnostic observation schedule. J Autism Dev Disord 1995; 25: 355-379.

33. Joseph RM, Tager-Flusberg H, Lord C. Cognitive profiles and social-communicative functioning in children with autism spectrum disorder. J Child Psychol Psychiatry 2002; 43 807-821.

34. Lord C, Leventhal BL, Cook Jr EH. Quantifying the phenotype in autism spectrum disorders. Am J Med Genet 2001; 105: 36-38.

35. Owley T, McMahon W, Cook EH, Laulhere T, South M, Mays LZ et al. Multisite, doubleblind, placebo-controlled trial of porcine secretin in autism. J Am Acad Child Adolesc Psychiatry 2001; 40: 1293-1299.

36. APA. Diagnostic and Statistical Manual of Mental Disorders: DSM-IV. 4th edn American Psychiatric Association: Washington, DC, 1994

37. Steinhausen HC, Erdin A. Abnormal psychosocial situations and ICD-10 diagnoses in children and adolescents attending a psychiatric service. J Child Psychol Psychiatry 1992 33: $731-740$

38. Braunschweig D, Duncanson P, Boyce R, Hansen R, Ashwood P, Pessah I et al Behavioral correlates of maternal antibody status among children with autism. $J$ Autism Dev Disord 2011 (in press).

39. Birchmeier C, Birchmeier W, Gherardi E, Vande Woude GF. Met, metastasis, motility and more. Nat Rev Mol Cell Biol 2003; 4: 915-925.

40. Huh CG, Factor VM, Sanchez A, Uchida K, Conner EA, Thorgeirsson SS. Hepatocyte growth factor/c-met signaling pathway is required for efficient liver regeneration and repair Proc Natl Acad Sci USA 2004; 101: 4477-4482.

41. Tahara Y, Ido A, Yamamoto S, Miyata Y, Uto H, Hori T et al. Hepatocyte growth factor facilitates colonic mucosal repair in experimental ulcerative colitis in rats. J Pharmacol Exp Ther 2003; 307: 146-151.

42. Arthur LG, Schwartz MZ, Kuenzler KA, Birbe R. Hepatocyte growth factor treatment ameliorates diarrhea and bowel inflammation in a rat model of inflammatory bowel disease. J Pediatr Surg 2004; 39: 139-143; discussion 139-143.
43. Ido A, Numata M, Kodama M, Tsubouchi $H$. Mucosal repair and growth factors: recombinant human hepatocyte growth factor as an innovative therapy for inflammatory bowel disease. J Gastroenterol 2005; 40: 925-931.

44. Beilmann M, Odenthal M, Jung W, Vande Woude GF, Dienes HP, Schirmacher P. Neoexpression of the c-met/hepatocyte growth factor-scatter factor receptor gene in activated monocytes. Blood 1997; 90: 4450-4458.

45. Beilmann M, Vande Woude GF, Dienes HP, Schirmacher P. Hepatocyte growth factorstimulated invasiveness of monocytes. Blood 2000; 95: 3964-3969.

46. Ito W, Kanehiro A, Matsumoto K, Hirano A, Ono K, Maruyama H et al. Hepatocyte growth factor attenuates airway hyperresponsiveness, inflammation, and remodeling. Am J Respir Cell Mol Biol 2005; 32: 268-280.

47. Yamaura K, Ito K, Tsukioka K, Wada Y, Makiuchi A, Sakaguchi M et al. Suppression of acute and chronic rejection by hepatocyte growth factor in a murine model of cardiac transplantation: induction of tolerance and prevention of cardiac allograft vasculopathy. Circulation 2004; 110: 1650-1657.

48. Adams DH, Harvath L, Bottaro DP, Interrante R, Catalano G, Tanaka Y et al. Hepatocyte growth factor and macrophage inflammatory protein 1 beta: structurally distinct cytokines that induce rapid cytoskeletal changes and subset-preferential migration in T cells. Proc Natl Acad Sci USA 1994; 91: 7144-7148.

49. Chen Q, DeFrances MC, Zarnegar R. Induction of met proto-oncogene (hepatocyte growth factor receptor) expression during human monocyte-macrophage differentiation. Cell Growth Differ 1996; 7: 821-832.

50. van der Voort R, Taher TE, Keehnen RM, Smit L, Groenink M, Pals ST. Paracrine regulation of germinal center B cell adhesion through the c-met-hepatocyte growth factor/ scatter factor pathway. J Exp Med 1997; 185: 2121-2131.

51. Galimi F, Cottone E, Vigna E, Arena N, Boccaccio C, Giordano S et al. Hepatocyte growth factor is a regulator of monocyte-macrophage function. $J$ Immunol 2001; 166: 1241-1247.

52. Benkhoucha M, Santiago-Raber M-L, Schneiter G, Chofflon M, Funakoshi H, Nakamura T et al. Hepatocyte growth factor inhibits CNS autoimmunity by inducing tolerogenic dendritic cells and CD25+Foxp3+ regulatory T cells. Proc Natl Acad Sci USA 2010; 107 : 6424-6429.

53. Coudriet GM, He J, Trucco M, Mars WM, Piganelli JD. Hepatocyte growth factor modulates interleukin-6 production in bone marrow derived macrophages: implications for inflammatory mediated diseases. PLOS ONE 2010; 5: e15384.

54. Ashwood P, Wakefield AJ. Immune activation of peripheral blood and mucosal CD3+ lymphocyte cytokine profiles in children with autism and gastrointestinal symptoms. J Neuroimmunol 2006; 173: 126-134.

55. Jyonouchi $\mathrm{H}$, Geng L, Ruby A, Zimmerman-Bier B. Dysregulated innate immune responses in young children with autism spectrum disorders: their relationship to gastrointestinal symptoms and dietary intervention. Neuropsychobiology 2005; 51: 77-85

56. Jyonouchi H, Geng L, Cushing-Ruby A, Quraishi H. Impact of innate immunity in a subset of children with autism spectrum disorders: a case control study. J Neuroinflammation 2008; 5: 52.

57. Molloy CA, Morrow AL, Meinzen-Derr J, Schleifer K, Dienger K, Manning-Courtney P et al. Elevated cytokine levels in children with autism spectrum disorder. J Neuroimmunol 2006; 172: 198-205.

58. Li X, Chauhan A, Sheikh AM, Patil S, Chauhan V, Li X-M et al. Elevated immune response in the brain of autistic patients. J Neuroimmunol 2009; 207: 111-116.

59. Gupta S, Aggarwal S, Rashanravan B, Lee T. Th1- and Th2-like cytokines in CD4+ and CD8+ T cells in autism. $J$ Neuroimmunol 1998; 85: 106-109.

60. Croonenberghs J, Bosmans E, Deboutte D, Kenis G, Maes M. Activation of the inflammatory response system in autism. Neuropsychobiology 2002; 45: 1-6.

61. Emanuele E, Orsi P, Boso M, Broglia D, Brondino N, Barale $\mathrm{F}$ et al. Low-grade endotoxemia in patients with severe autism. Neurosci Lett 2010; 471: 162-165.

Translational Psychiatry is an open-access journal published by Nature Publishing Group. This work is licensed under the Creative Commons Attribution-NoncommercialNo Derivative Works 3.0 Unported License. To view a copy of this license, visit http://creativecommons.org/licenses/by-nc-nd/3.0/ 